\title{
Assessment of the antidepressant effect of caffeine using rat model of depression induced by reserpine
}

\author{
Yasser A. Khadrawy ${ }^{*}$ (D, Hussein G. Sawie, Eman N. Hosny and Hagar H. Mourad
}

\begin{abstract}
Objective: The present objective is to evaluate the antidepressant activity of caffeine.

Material and methods: Three groups of rats were used; control, reserpine-induced rat model of depression, and rat model of depression treated daily with caffeine. At the end of the experiment, the motor activity of rats was measured using open field test. On the next day, the animals of the three groups were sacrificed to measure levels of serotonin, norepinephrine, and dopamine in the cortex and hippocampus by spectrofluorometer. In addition, the levels of lipid peroxidation (MDA), nitric oxide (NO), and reduced glutathione (GSH) together with the activities of acetylcholinesterase (AchE) and $\mathrm{Na}^{+}, \mathrm{K}^{+}$, ATPase were measured in the two studied brain regions by spectrophotometer.

Results: In the rat model of depression, the animals showed a significant decrease in motor activity. This was associated with significant decreases in serotonin, norepinephrine, and dopamine in the cortex and hippocampus. However, significant increases in the activities of AchE and $\mathrm{Na}^{+}, \mathrm{K}^{+}$, ATPase, and the levels of MDA and NO were recorded in both areas of rat model of depression while GSH showed a significant decrease in the hippocampus. Caffeine failed to restore the decrease in motor activity. Caffeine treatment ameliorated the changes in cortical and hippocampal norepinephrine and dopamine and hippocampal serotonin. In addition, it restored MDA and GSH levels. However, it failed to prevent the increased AchE and $\mathrm{Na}^{+}, \mathrm{K}^{+}$, ATPase activities, and $\mathrm{NO}$ levels.

Conclusions: The present findings indicate that caffeine has a partial antidepressant effect mediated by its antioxidant activity and enhancement of monoamine levels.
\end{abstract}

Keywords: Depression, Caffeine, Monoamines, Oxidative stress, Acetylcholinesterase

\section{Background}

Caffeine (1,3,7-trimethylxanthine) is a psychoactive agent that is used worldwide in different forms. Due to its lipophilicity, caffeine crosses the blood-brain barrier easily exerting its stimulant effect (Ferré 2016). Caffeine exerts its activity on the central nervous system (CNS) by counteracting most of the inhibitory effects of adenosine on neuroexcitability (Fredholm et al. 1999), arousal (PorkkaHeiskanen 1999), and spontaneous activity (Kuzmin et al. 2006). Also, the changes induced by caffeine in CNS functions were mediated by reducing phosphodiesterase activity, blocking GABA-A receptor activity, and increasing intracellular calcium (Garrett and Griffiths 1997). The

\footnotetext{
* Correspondence: yaserask@yahoo.com

Department of Medical Physiology, Medical Division, National Research Center, El-Behouth St., Giza, Egypt
}

stimulatory effect of caffeine has been attributed to its antagonistic effect on the activity of endogenous adenosine inhibiting the release of several CNS neurotransmitter systems including $\gamma$-aminobutyric acid (GABA), acetylcholine, glutamate, dopamine, norepinephrine, and serotonin (El Yacoubi et al. 2001; Ferré et al. 1996a; Ferré et al. 1996b; Fisone et al. 2004; Williams 1987) and thus the effect of caffeine on depression has been taken into consideration.

The preclinical and clinical findings indicate that there is a close relationship between the adenosine modulatory system and depressive-like behavior (Blardi et al. 2005). Under normal physiological conditions, adenosine acts as a neuromodulator in the CNS through activating adenosine receptors $A_{1}$ and $A_{2} A$ in the brain resulting in inhibition of synaptic activity and neurotransmitter release (Fredholm 
et al. 2005). It has been observed that methylxanthines including caffeine could block these adenosine receptors (Fredholm et al., 1999).

Depression is an important public health issue. By 2030, it is expected that depression will be one of the third disorders contributing to the universal disease burden (Mathers and Loncar 2006). According to the current World Health Organization (WHO) estimation, the number of people suffering from depressive disorders worldwide is 350 million. In addition, WHO predicts that depression will be the second civilization disorder producing incapacity by 2020 .

There are controversial data on the relation between the consumption of caffeine and depression. Several epidemiologic studies have found a connection between coffee or caffeine intake and depression, but the results of existing literature have yielded inconsistent results. Some studies discovered an inverse relationship between coffee or caffeine and depression (Guo et al. 2014; Pham et al. 2014). Recently, Wang et al. (2016) in a meta-analysis of observational studies found that coffee and caffeine intake were significantly linked with reduced risk of depression. Other studies did not find any beneficial effect for coffee and caffeine on depression (Pham et al. 2014; Ruusunen et al. 2010). On the other hand, the study of Jin et al. (2016) concluded that caffeine intake was positively related to severity of depression and insomnia among Korean adolescents.

According to the monoamine hypothesis of depression, the brain depletion of serotonin, norepinephrine, and/or dopamine could underlie the etiology and pathogenesis of depression (Schechter et al. 2005). In addition, several lines of evidence indicate the involvement of oxidative and nitrosative stress in the pathophysiology of depressive disorders (Maes et al. 2011).

Therefore, the current study aims to evaluate the effect of caffeine on the behavioral (open field test) and neurochemical (the levels of serotonin, norepinephrine, dopamine, lipid peroxidation, nitric oxide, and reduced glutathione and the activities of acetylcholinesterase and $\mathrm{Na}^{+}, \mathrm{K}^{+}$, ATPase) changes occurring in the hippocampus and cerebral cortex of depressive-like rats induced by reserpine.

\section{Material and methods \\ Animals}

Twenty-four male Wistar rats, weighing between 230 and $250 \mathrm{~g}$, were obtained from the Animal House of the National Research Centre, Egypt. They were housed under temperature- and light-controlled conditions with standard laboratory rodent chow and water provided ad libitum. Animal procedures were approved by the Ethics Committee of the National Research Centre and were performed in compliance with the recommendations of the
National Institutes of Health Guide for Care and Use of Laboratory Animals (publication no. 85-23, revised 1985).

\section{Chemicals}

Reserpine (Mallinckrodlt. Inc., Martin Luther King Jr. Blvd, Paris-Kantucky) was dissolved in glacial acetic acid $(1 \mu \mathrm{g} / \mu \mathrm{l})$ and then completed to $25 \mathrm{ml}$ with distilled water. Caffeine was purchased from Global Chemie (Mombai, India). It was dissolved in $0.9 \%$ saline $(15 \mathrm{mg} / \mathrm{ml})$. All other reagents were obtained from Sigma Chemical Co. (St. Louis MO, USA).

\section{Experimental design}

At the beginning of the experiment, the rats were divided randomly into control rats that received the vehicle till the end of experiment and reserpine-treated rats that were injected intraperitoneally (i.p.) with reserpine $(0.2 \mathrm{mg} / \mathrm{kg} /$ day) for 15 days to establish the animal model of depression according to Antkiewicz-Michaluk et al. (2014). On the 16th day, the reserpine-treated rats were further divided into two groups: rat model of depression that continued receiving an i.p. injection of reserpine $(0.1 \mathrm{mg} / \mathrm{kg} /$ day) for further 15 days to keep the state of depression and rat model of depression in which rats were treated daily with an i.p. injection of reserpine $(0.1 \mathrm{mg} / \mathrm{kg} /$ day $)$ followed by an i.p. injection of caffeine $(30 \mathrm{mg} / \mathrm{kg})$ with 1 -h interval between the two drugs for 15 days.

\section{Behavioral analysis}

The open field test was used at the end of the experiment for the control, depressed rats, and depressed rats treated with caffeine to screen the impairment in motor activity.

\section{The open field test}

The open field apparatus was constructed of white plywood and measured $72 \times 72 \mathrm{~cm}$ with $36 \mathrm{~cm}$ walls. One of the walls was clear Plexiglas, so rats could be visible in the apparatus. Blue lines were drawn on the floor with a marker and were visible through the clear Plexiglas floor. The lines divided the floor into $1618 \times$ $18 \mathrm{~cm}$ squares. A central square $(18 \mathrm{~cm} \times 18 \mathrm{~cm})$ was drawn in the middle of the open field. Rats were placed individually in the center of the open-field and behavioral parameters were assessed manually for $10 \mathrm{~min}$. Five motor parameters were quantified throughout this test: central square duration (the duration of time the rats spent in the central square), line crossings (the number of times the rats crossed one of the grid lines with all four paws), rearing (the number of times the rats stood on their hind legs in the maze), freezing time (duration in which the rat was completely stationary), and grooming (number of body-cleaning with paws, licking of the body and pubis with the mouth, and face-washing actions). The 
open field apparatus was cleaned after each session using $70 \%$ ethyl alcohol and permitted to dry between tests (Brown et al. 1999).

Following behavioral testing, the animals were sacrificed by sudden decapitation. The brain of each animal was quickly removed and rapidly transferred to an ice-cold Petri dish. Each brain was divided into two halves; right and left. Each half was dissected to obtain the cortex and hippocampus. The right half of each rat was used to measure the oxidative stress parameters and enzyme activities. The left half was used to measure serotonin, norepinephrine, and dopamine neurotransmitters. Each brain area was weighed and frozen at $-80{ }^{\circ} \mathrm{C}$ until analyzed.

\section{Neurotransmitter analysis}

The right halves of each cortex and hippocampus were homogenized in an ice-cold solution of acidified $n$-butanol. The homogenates were centrifuged at $2000 \mathrm{rpm}$ for $5 \mathrm{~min}$. The supernatants were used for the estimation of dopamine (DA), norepinephrine (NE), and serotonin (5-hydroxytryptamine; 5-HT) according to the fluorometric method described by Ciarlone (Ciarlone 1978). The fluorescence was measured using a spectrofluorometer (model Jasco-FP-6500, Japan) with a source of xenon arc lamp $150 \mathrm{~W}$.

\section{Analysis of oxidative stress parameters and enzymes' activities}

The left halves of each cortex and hippocampus were homogenized in Tris- $\mathrm{HCl}$ buffer ( $\mathrm{pH} 7.4)$. The homogenate was centrifuged at $5000 \mathrm{rpm}$ and $4{ }^{\circ} \mathrm{C}$ for $10 \mathrm{~min}$. The supernatant was stored at $-70{ }^{\circ} \mathrm{C}$ until analysis. This supernatant was used to analyze the following parameters.

\section{Determination of lipid peroxidation}

Malondialdehyde (MDA), a measure of membrane lipid peroxidation, was estimated according to the method of Ruiz-Larrea et al. (1994). MDA was determined by measuring thiobarbituric reactive species (TBARS). One molecule of MDA reacts with two molecules of thiobarbituric acid in acidic medium at temperature of $95{ }^{\circ} \mathrm{C}$ for $20 \mathrm{~min}$ to form thiobarbituric acid reactive substances; the absorbance of the resultant pink product was measured at $532 \mathrm{~nm}$ using UV-visible spectrophotometer (model UV-2401 PC, Shimadzu, Japan).

\section{Determination of nitric oxide}

Nitric oxide (NO) was determined spectrophotometrically in the brain tissue according to the method described by Moshage et al. (1995). This method is based on the measurement of endogenous nitrite concentration as an indicator of nitric oxide production. It depends on the addition of Griess reagent which converts nitrite into a deep purple azo compound whose absorbance is read at $540 \mathrm{~nm}$.

\section{Determination of reduced glutathione}

Reduced glutathione (GSH) level in the selected brain regions was determined by the method of Moron et al. (1979). This method is based on the reduction of 5,5' dithiobis-(2-nitrobenzoic acid) or DTNB "Ellman's reagent" with GSH to produce a yellow compound. The reduced chromogen is directly proportional to GSH concentration and its absorbance is measured at $412 \mathrm{~nm}$. Total GSH content was expressed in $\mathrm{mmol} / \mathrm{g}$ brain tissue.

\section{Determination of acetylcholinesterase activity}

Acetylcholinesterase (AchE) activity was measured according to the modified method of Gorun et al. (1978). The principle of the method depends on the hydrolysis of acetylthiocholine iodide by acetylcholinesterase to produce thiocholine. Thiocholine is allowed to react with the -SH reagent 5,5'-dithiobis-(2-nitrobenzoic acid) (DTNB), which is reduced to thionitrobenzoic acid, a yellow colored anion whose absorption is read spectrophotometrically at $412 \mathrm{~nm}$. The results were expressed as $\mu \mathrm{mol} \mathrm{SH} / \mathrm{min} / \mathrm{g}$ brain tissue.

\section{Determination of $\mathrm{Na}^{+}, \mathrm{K}^{+}$, ATPase activity}

$\mathrm{Na}^{+}, \mathrm{K}^{+}$, ATPase activity was measured spectrophotometrically according to Tsakiris et al. (2000). $\mathrm{Na}^{+}, \mathrm{K}^{+}$, ATPase activity was calculated as the difference between total ATPase activity $\left(\mathrm{Na}^{+}, \mathrm{K}^{+}\right.$, ATPase, and Mg-ATPase activity) and Mg-ATPase activity.

\section{Statistical analysis}

The data were expressed as means \pm S.E.M. Statistical significance between the groups under investigation was tested by one-way analysis of variance (ANOVA) using Statistical Package for Social Sciences (SPSS) program followed by Duncan as post-hoc test to compare the significance between groups. The difference was considered significant at $p$ value $<0.05$.

\section{Results \\ Neurochemical results}

In the cortex of rat model of depression, a significant decrease in the levels of serotonin (-55.3\%) and norepinephrine $(-14.6 \%)$ was recorded in comparison to control values. In the hippocampus, there was a significant decrease in serotonin, norepinephrine, and dopamine recording $48.2 \%,-45.9 \%$, and $-35.5 \%$, in comparison to control animals. When the depressive-like rats were treated daily with caffeine, it failed to restore the level of cortical serotonin but elevated the reduced level of norepinephrine to control-like value. In the hippocampus, caffeine improved the levels of serotonin, norepinephrine, and dopamine to nonsignificant changes as compared to control value (Table 1).

The present findings showed that cortical and hippocampal AchE activity increased significantly in rat model 
Table 1 Effect of daily caffeine treatment (30 mg/ $\mathrm{kg})$ on the level of serotonin $(\mu \mathrm{g} / \mathrm{g})$, norepinephrine $(\mu \mathrm{g} / \mathrm{g})$, and dopamine $(\mu \mathrm{g} / \mathrm{g})$ in the cortex and hippocampus of rat model of depression induced by reserpine

\begin{tabular}{llllllrr}
\hline & & Control & Depressed rat model & $\%$ D & \multicolumn{2}{l}{$\begin{array}{l}\text { Depressed rats treated } \\
\text { with caffeine }\end{array}$} & \%D value \\
\hline Cortex & Serotonin & $0.166^{\mathrm{a}} \pm 0.027(6)$ & $0.074^{\mathrm{b}} \pm 0.008(7)$ & -55.30 & $0.104^{\mathrm{b}} \pm 0.013(7)$ & -37.34 & 009 \\
& Norepinephrine & $0.155^{\mathrm{a}} \pm 0.004(6)$ & $0.129^{\mathrm{b}} \pm 0.003(7)$ & -14.57 & $0.160^{\mathrm{a}} \pm 0.009(7)$ & 5.96 & 0.028 \\
& Dopamine & $0.904^{\mathrm{a}} \pm 0.074(6)$ & $0.713^{\mathrm{a}} \pm 0.066(6)$ & -21.12 & $0.850^{\mathrm{a}} \pm 0.052(7)$ & -5.97 & 0.151 \\
Hippocampus & Serotonin & $0.526^{\mathrm{a}} \pm 0.074(6)$ & $0.231^{\mathrm{b}} \pm 0.031(6)$ & -48.20 & $0.581^{\mathrm{a}} \pm 0.087(6)$ & 10.45 & 0.008 \\
& Norepinephrine & $0.477^{\mathrm{a}} \pm 0.095(6)$ & $0.258^{\mathrm{b}} \pm 0.030(6)$ & -45.91 & $0.537^{\mathrm{a}} \pm 0.081(6)$ & 12.57 & 0.026 \\
& Dopamine & $1.220^{\mathrm{a}} \pm 0.078(6)$ & $0.790^{\mathrm{b}} \pm 0.043(6)$ & -35.24 & $1.468^{\mathrm{a}} \pm 0.073(6)$ & 20.32 & 0.004 \\
\hline
\end{tabular}

Values represent mean \pm S.E. with the number of animals between parentheses

$\% D$ difference with respect to control values

Different letters indicate significantly different means $p$ value $<0.05$

Same letters indicate nonsignificant changes

of depression recording $114.1 \%$ and $83.3 \%$ above the control values, respectively. Similarly, cortical and hippocampal $\mathrm{Na}^{+}, \mathrm{K}^{+}$, ATPase activity increased significantly (37.6\% and $30.02 \%$, respectively) in reserpine-treated rats. Although caffeine reduced the cortical and hippocampal AchE activity to $66.2 \%$ and $51.9 \%$, respectively, its value still showed a significant increase above than the control value. However, caffeine treatment normalized cortical and hippocampal $\mathrm{Na}^{+}, \mathrm{K}^{+}$, ATPase activities (Table 2).

In the depressive-like rat model induced by reserpine, the lipid peroxidation level increased significantly in the cortex (41.9\%) and hippocampus (78.3\%) as compared to control values. This increase returned to control-like values after daily caffeine treatment. However, caffeine treatment failed to prevent the significant increase in cortical and hippocampal nitric oxide levels induced by reserpine. The significant decrease in GSH level that was observed in the hippocampus of rat model of depression returned to a control-like value after caffeine treatment. In the cortex, GSH level increased significantly after caffeine treatment (Table 3).

\section{Behavioral results}

As demonstrated in (Fig. 1), the animals representing the depression model exhibited a significant reduction in the crossed lines, rearings, and grooming. In addition, significant increases in the time spent in the central square and freezing time were recorded in the animal model of depression when compared to control rats. Unfortunately, caffeine failed to induce any improvement in the open field parameters except for the grooming behavior that was reversed to a significant increase.

\section{Discussion}

In the current study, the reserpine-induced depressivelike rat model was used to evaluate whether caffeine could treat depression or exaggerate it.

The present data revealed that the daily reserpine treatment for 30 days induced a significant decrease in cortical and hippocampal serotonin, norepinephrine and dopamine levels. In addition, a decrease in motor activity was observed. This was evident from the data of the open field test that exhibited significant decreases in the number of line crossings, rearings, and groomings and significant increases in the time spent in the central square and freezing time.

Immobility is an indicator of hopeless feelings and despair (Holmes 2003). Depression and immobility are proposed to be correlated with each other and it has already been shown that antidepressant drugs reduce immobility (Gersner et al. 2009).

Table 2 Effect of daily caffeine treatment ( $30 \mathrm{mg} / \mathrm{kg}$ ) on the activity of acetylcholinesterase (AchE) ( $\mu \mathrm{mol} \mathrm{SH} / \mathrm{g} / \mathrm{min})$ and Na, $\mathrm{k}$, ATPase $(\mu \mathrm{mol} \mathrm{Pi} / \mathrm{min} / \mathrm{g})$ in the cortex and hippocampus of rat model of depression induced by reserpine

\begin{tabular}{llllllrr}
\hline & & Control & Depressed rat model & $\%$ D & \multicolumn{2}{l}{$\begin{array}{l}\text { Depressed rats treated } \\
\text { with caffeine }\end{array}$} & \%D \\
\hline Cortex & AchE & $3.307^{\mathrm{a}} \pm 0.772(6)$ & $7.080^{\mathrm{b}} \pm 0.546(6)$ & 114.1 & $5.495^{\mathrm{b}} \pm 0.031(6)$ & 66.16 & 0.011 \\
& Na, K, ATPase & $0.181^{\mathrm{a}} \pm 0.010(6)$ & $0.249^{\mathrm{b}} \pm 0.021(6)$ & 37.57 & $0.174^{\mathrm{a}} \pm 0.010(6)$ & -3.87 & 0.018 \\
Hippocampus & AchE & $6.047^{\mathrm{a}} \pm 1.588(6)$ & $11.084^{\mathrm{b}} \pm 1.390(7)$ & 83.29 & $9.18^{\mathrm{c}} \pm 0.505(6)$ & 51.89 & 0.027 \\
& Na, K, ATPase & $0.523^{\mathrm{a}} \pm 0.024(6)$ & $0.680^{\mathrm{b}} \pm 0.081(6)$ & 30.02 & $0.493^{\mathrm{a}} \pm 0.019(7)$ & -5.73 & 0.018 \\
\hline
\end{tabular}

Values represent mean \pm S.E. with the number of animals between parentheses

$\% D$ difference with respect to control values

Different letters indicate significantly different means $p$ value $<0.05$

Same letters indicate nonsignificant changes 
Table 3 Effect of daily caffeine treatment (30 mg/kg) on the levels of lipid peroxidation (MDA) (nmol/g), reduced glutathione (GSH) $(\mathrm{mmol} / \mathrm{g})$, and nitric oxide (NO) ( $\mathrm{mmol} / \mathrm{g})$ in the cortex and hippocampus of rat model of depression induced by reserpine

\begin{tabular}{llllllll}
\hline & & Control & Depressed rat model & \% D & \multicolumn{2}{c}{$\begin{array}{l}\text { Depressed rats treated } \\
\text { with caffeine }\end{array}$} & \%D \\
\hline Cortex & MDA & $7.326^{\mathrm{a}} \pm 0.786(6)$ & $10.373^{\mathrm{b}} \pm 1.147(6)$ & 41.59 & $7.687^{\mathrm{a}} \pm 0.792(6)$ & 4.93 & 0.027 \\
& GSH & $6.445^{\mathrm{a}} \pm 0.138(7)$ & $6.080^{\mathrm{a}} \pm 0.280(7)$ & -5.66 & $7.093^{\mathrm{b}} \pm 0.226(7)$ & 10.05 & 0.026 \\
& NO & $0.194^{\mathrm{a}} \pm 0.016(6)$ & $0.240^{\mathrm{b}} \pm 0.014(6)$ & 23.71 & $0.272^{\mathrm{b}} \pm 0.013(7)$ & 40.21 & 0.010 \\
Hippocampus & MDA & $5.046^{\mathrm{a}} \pm 0.798(6)$ & $9.827^{\mathrm{b}} \pm 1.895(6)$ & 78.25 & $4.516^{\mathrm{a}} \pm 1.033(6)$ & -10.50 & 0.008 \\
& GSH & $15.406^{\mathrm{a}} \pm 0.328(6)$ & $13.031^{\mathrm{b}} \pm 0.531(6)$ & -15.42 & $15.879^{\mathrm{a}} \pm 0.625(7)$ & 3.07 & 0.015 \\
& NO & $0.459^{\mathrm{a}} \pm 0.044(6)$ & $0.825^{\mathrm{b}} \pm 0.082(6)$ & 79.74 & $0.564 \mathrm{a}^{\mathrm{b}} \pm 0.039(7)$ & 22.87 & 0.010 \\
\hline
\end{tabular}

Values represent mean \pm S.E. with the number of animals between parentheses

$\% D$ difference with respect to control values

Different letters indicate significantly different means $p$ value $<0.05$

Same letters indicate nonsignificant changes

Time spent in the central square

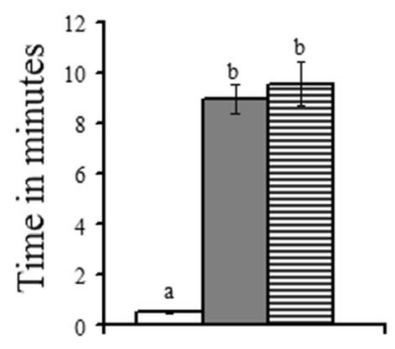

No. of groomings

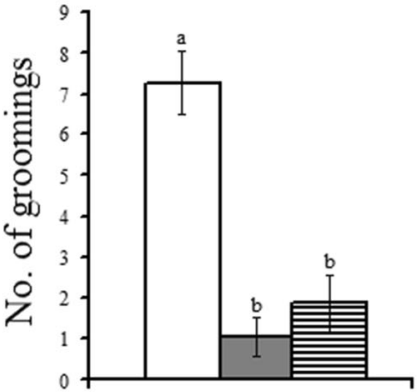

Freezing time

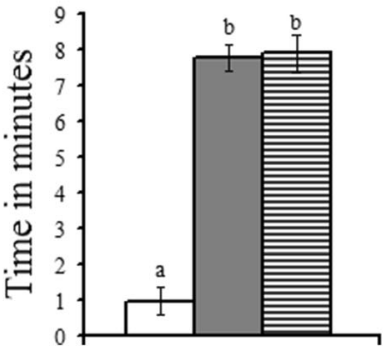

No. of crossed squares

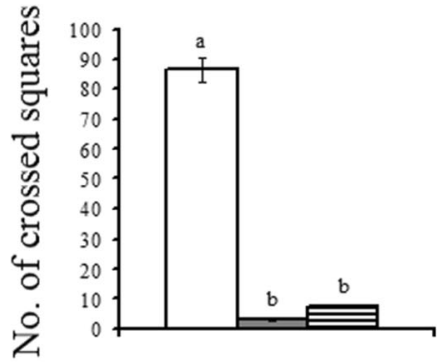

No. of rearings

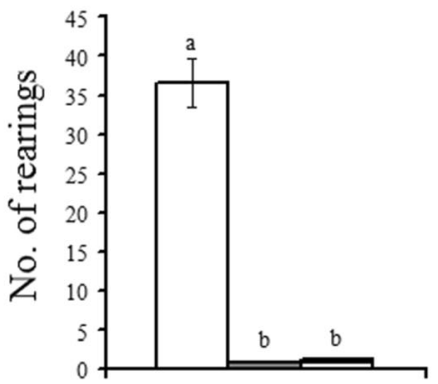

Fig. 1 Effect of daily caffeine treatment ( $30 \mathrm{mg} / \mathrm{kg}$ ) on the open field test parameters in rat model of depression induced by reserpine. $\square$ control. rat model of depression. $\equiv$ rat model of depression treated with caffeine. Statistically significant means $(p$ value $<0.05)$ are given different letters. Nonsignificant means are given the same letters 
Several studies suggested that the depletion of cerebral monoamines represents the main cause for the pathogenesis of depression (Dale et al. 2015). Supporting this suggestion, the action of current antidepressants depends mainly on elevating levels of monoamines specially serotonin by selective serotonin reuptake inhibitors (Jakobsen et al. 2017) or monoamine oxidase inhibitors (Youdim et al. 2006). Therefore, the significant decrease in monoamines associated with the decrease in motor activity induced by reserpine indicates the development of rat model of depression. This model was used successfully by many studies to investigate the antidepressant effect of many agents (Antkiewicz-Michaluk et al. 2014). Reserpine could deplete monoamines by inhibiting the activity of vesicular monoamine transporter-2 (VMAT-2) (Erickson et al. 1992). This effect prevents the reuptake of monoamines into the synaptic vesicles exposing them to oxidative catabolism by the cytosolic enzyme monoamine oxidase (Antkiewicz-Michaluk et al. 2014). This mechanism could explain the decreased monoamine levels reported in the present study.

As a consequence to the oxidative catabolism of cytosolic dopamine, norepinephrine, and serotonin by monoamine oxidase, the cellular oxidant, hydrogen peroxide is produced (Youdim et al. 2006). In addition, monoamines, especially dopamine and norepinephrine, can undergo spontaneous cytoplasmic oxidation leading to the destruction of cellular structures (Wasik et al. 2009). These reactions produce several potentially neurotoxic byproducts, such as hydrogen peroxide (Barros-Miñones et al. 2015). Hydrogen peroxide can result in the generation of reactive oxygen species and induce neuronal apoptosis due to mitochondrial damage (Bortolato et al. 2008). The present findings revealed a state of oxidative stress after reserpine treatment in both the cortex and hippocampus. This was evident from the significantly increased lipid peroxidation (MDA) and nitric oxide (NO) levels together with the significantly decreased reduced glutathione (GSH). Under such conditions of inhibition of VMAT-2 induced by reserpine and the effect of monamine oxidase, the oxidative catabolism may explain the present oxidative stress observed in the cortex and hippocampus of reserpine-induced rat model of depression. Moreover, the observed increased MDA levels may arise from the attack of the neuronal membrane phospholipids by free radicals produced from monoamine catabolism. Malondialdehyde is produced from decomposition of products of lipid peroxidation (Gaweł et al. 2004). In addition, the cortical and hippocampal increase in NO may be mediated by the increased inducible nitric oxide synthase (iNOS) and neuronal NOS expression that have been reported in depressed rats and rats subjected to immobilization stress (Gałecki et al. 2012; Maes et al. 2011).

Our results are in agreement with several studies which showed that oxidative stress is a contributing factor in the pathogenesis of psychiatric illness including depression to the extent that antioxidants have been suggested as neuroprotectors against depression (Behr and Moreira 2012). Moreover, oxidative stress may represent the mechanism underlying the neurodegeneration observed in depression and may explain the reduced volume of hippocampus (Arnone et al., 2012).

Charles et al. (1994) found an increase in choline, the rate-limiting precursor in the synthesis of acetylcholine in the brains of depressed patients compared to normal controls. Higley and Picciotto (2014) reported that the enhancement of ACh signaling can induce depressive symptoms in humans and animal models. Using human imaging, Saricicek et al. (2012) suggested that the levels of ACh are increased in patients with active depression, as assessed by the occupation of nicotinic receptors all over the brain, and remain elevated in patients with a history of depression. This may support the hypothesis relating adrenergic-cholinergic balance with depression and mania (Janowsky et al. 1972). This hypothesis suggests that elevated cholinergic tone and reduced noradrenergic tone may cause depressive symptoms and has been supported by several lines of evidence from rodent and human studies (Mineur et al. 2013). Several selective monoamine reuptake inhibitors have been characterized as nicotinic ACh receptor antagonists (Fryer and Lukas 1999; Hennings et al. 1999). AchE is the enzyme responsible for catabolism of ACh to terminate its action. Therefore, the increased AchE activity observed in the present study may be attributed to the increased ACh, AchE substrate. Also, this increase in AchE may represent a compensatory mechanism to attenuate the increase in cholinergic activity that has been reported in depression.

The increase of neuronal excitability in the CNS can consume much of the energy of the cells. It has been estimated that more than one half of the total ATP produced in the brain at rest is used up by $\mathrm{Na}+\mathrm{K}+$, ATPase to maintain the proper ionic gradients across the cell membrane (Erecińska and Silver 1989). $\mathrm{Na}^{+}, \mathrm{K}^{+}$, ATPase activity acts to restore the membrane action potential by the efflux of $\mathrm{Na}$ ions and influx of $\mathrm{K}$ ions (Albers and Siegel 2012). Therefore, decreased $\mathrm{Na}^{+}, \mathrm{K}^{+}$, ATPase activity has been reported with increased excitability (Souza et al. 2013). This is due to its exhaustion in restoring ionic gradients across the cell membrane. Thus, under the present conditions of depression and reduced neuronal excitability, the increase in the activity of $\mathrm{Na}^{+}, \mathrm{K}^{+}$, ATPase was expected.

The present findings indicate that the decrease in cortical serotonin level induced in rat model of depression continued after caffeine treatment. However, caffeine restored cortical norepinephrine and dopamine to control-like values. In the hippocampus, caffeine treatment resulted in nonsignificant increases in serotonin, norepinephrine, 
and dopamine levels. It is clear that caffeine has a partial antidepressant effect.

It has been reported that caffeine has a stimulatory effect on tyrosine hydroxylase, the rate-limiting enzyme in catecholamine synthesis (Hsu et al. 2010) and an inhibitory effect on monoamine oxidase enzyme, the monoamines catabolizing enzyme (Akomolafe et al. 2017). These effects of caffeine could explain the recovery in cortical and hippocampal norepinephrine and dopamine. Moreover, the inhibitory effect of caffeine on monamine oxidase activity may underlie the amelioration in hippocampal serotonin level. The present data is supported by the study of Fredholm (1995) who found that caffeine can elevate the reduced levels of monoamine neurotransmitters recorded in depressive disorders, an effect mediated by antagonizing $A_{1}$ adenosine receptor. In addition, one of the important steps toward the treatment of depression is the stimulatory effect of caffeine on the release of serotonin in the limbic brain regions and dopamine in the prefrontal cerebral cortex. This effect of caffeine resembles the action of antidepressants (Acquas et al. 2002; Fredholm 1995). Accordingly, the present increase in dopamine especially in the hippocampus may have a role in improving mood and the state of the depressive-like model. Dopamine is the neurotransmitter involved in regulation of mood and sense of well-being. In addition, the stimulatory effect of caffeine on the release of neurotransmitters including dopamine, norepinephrine, and serotonin may have a role in increasing the monoaminergic activity which is reduced in depression.

Although caffeine treatment failed to ameliorate the increased AchE activity induced in rat model of depression, there is a partial improvement in AchE activity from $114.1 \%$ and $83.3 \%$ to $66.2 \%$ and $51.9 \%$ in the cortex and hippocampus, respectively. Akomolafe et al. (2017) recorded an inhibitory effect of caffeine on AchE. This may be an indicator of the inability of caffeine to restore the cholinergic activity to its normal value.

The antioxidant activity of caffeine has been demonstrated (Aoyama et al. 2011). This effect has been attributed to its action as a ROS scavenger especially for the hydroxyl radicals $\left(\mathrm{OH}^{-}\right)$(Devasagayam et al. 1996; Shi et al. 1991). Additionally, caffeine has been shown to prevent Fenton's reaction-induced oxidation of GSH (Shi et al. 1991), a major nonenzymatic antioxidant reserve in many tissues, including the CNS. Thus, the antioxidant effect of caffeine obtained in the present study may be attributed to its inhibitory effect on monoamine oxidase which in turn may prevent the oxidative catabolism and formation of free radicals. The present ameliorating effect of caffeine on GSH may be mediated by the increase in GSH synthesis (Aoyama et al. 2011).

Several studies showed that caffeine significantly increased NO levels (Alasehirli et al. 2005; Hashiguchi et al. 2001).
This effect could be attributed to the activation of endothelial NOS leading to the increase in NO (Cappelletti et al. 2015). Therefore, the present elevation in the levels of cortical and hippocampal NO could be due to the activation of NOS. The increased cerebral NO level may induce vasodilating effect (Toda et al. 2009) and consequently increased cerebral blood flow. This effect may have a role in the beneficial effect exerted by caffeine on cognitive functions (Cunha and Agostinho 2010).

The present amelioration in $\mathrm{Na}^{+}, \mathrm{K}^{+}$, ATPase activity induced by caffeine may represent a step toward the improvement in the depression model. The recovery in $\mathrm{Na}^{+}$, $\mathrm{K}^{+}$, ATPase activity is an indicator of returning the normal polarity of the cell membrane.

The behavioral data showed that caffeine maintained the changes in open field test parameters induced by reserpine (a significant decrease in number of crossed lines, rearings, and groomings and a significant increase in the time spent in central square and freezing time).

It has been reported by several studies that caffeine has motor-stimulating effect (Nehlig et al. 1992). However, caffeine in the present study failed to induce any improvement in the deficits of motor activity induced by reserpine. This could be attributed to the tolerance of motor stimulation that has been observed with the chronic treatment of caffeine (Holtzman and Finn 1988; Karcz-Kubicha et al. 2003; Svenningsson et al. 1999). Caffeine induced a dose-dependent anxiogenic effect in rats as evident from the reduced rears and ambulation, and the increased immobility and defecation in the open-field test, and the increased number of entries and stay duration in the closed arms of the elevated plus-maze (Bhattacharya et al. 1997). Therefore, the inability of caffeine to restore the decrease in motor activity induced by reserpine, in the present study, may be attributed to the development of tolerance to the reported motor stimulant effect of caffeine on the one hand and the anxiogenic effect arising from the blocking of adenosine receptors $\left(\mathrm{A}_{1}\right.$ and $\left.\mathrm{A}_{2}\right)$ on the other hand.

The present findings indicate that caffeine improved monoamine levels, and $\mathrm{Na}^{+}, \mathrm{K}^{+}$, ATPase activity and prevented the increased lipid peroxidation and decreased GSH in the cortex and hippocampus. In addition, the increased level of NO in the two brain regions could have a vasodilating effect. However, caffeine failed to restore the activity of AchE in the cortex and hippocampus and cortical serotonin level and the reduced motor activity.

\section{Conclusion}

The present data showed that the daily caffeine treatment for 15 days induced a partial antidepressant effect. This effect was mediated by the increased level of cortical and hippocampal serotonin, norepinephrine, and dopamine. In addition, the antioxidant and vasodilating effect exerted 
by caffeine may also have a role in its antidepressant-like activity.

\section{Acknowledgements}

Not applicable.

\section{Funding}

Not applicable.

\section{Availability of data and materials}

The datasets obtained in the present study could be requested from the corresponding author.

\section{Authors' contributions}

YA Khadrawy suggested the idea, analyzed the results, and shared in writing the manuscript. HG Sawei shared in following the animals and collecting the data. EN Hosny contributed in following the animals, collecting the data, and statistical analysis. HH Mourad contributed in collecting the data and preparing the figures and tables. All the authors contributed in writing the manuscript. All authors read and approved the final manuscript.

\section{Ethics approval and consent to participate}

This work has been approved by the Ethics Committee of the National Research Centre (Number: 17131) and were performed in compliance with the recommendations of the National Institutes of Health Guide for Care and Use of Laboratory Animals (publication no. 85-23, revised 1985).

\section{Consent for publication}

Not applicable.

\section{Competing interests}

The authors declare that they have no competing interests.

\section{Publisher's Note}

Springer Nature remains neutral with regard to jurisdictional claims in published maps and institutional affiliations.

Received: 26 September 2018 Accepted: 25 November 2018 Published online: 29 December 2018

\section{References}

Acquas E, Tanda G, Di Chiara G (2002) Differential effects of caffeine on dopamine and acetylcholine transmission in brain areas of drug-naive and caffeine-pretreated rats. Neuropsychopharmacology 27:182-193

Akomolafe SF, Akinyemi AJ, Ogunsuyi OB, Oyeleye SI, Oboh G, Adeoyo OO, Allismith YR (2017) Effect of caffeine, caffeic acid and their various combinations on enzymes of cholinergic, monoaminergic and purinergic systems critical to neurodegeneration in rat brain-in vitro. Neurotoxicology 62:6-13

Alasehirli B, Cekmen M, Nacak M, Balat A (2005) Effects of caffeine on placental total nitrite concentration: a 21-day, vehicle-controlled study in rats. Curr Ther Res 66:130-137

Albers RW, Siegel Gl (2012) Membrane transport. In: Brady ST, Siegel GJ, Albers RW, Price D (eds) Basic neurochemistry: principles of molecular, cellular and medical neurobiology, 8th edn. Elsevier Academic Press, Massachusetts, USA, pp 41-62

Antkiewicz-Michaluk L. Wąsik A, Możdżeń E, Romańska I, Michaluk J (2014) Antidepressant-like effect of tetrahydroisoquinoline amines in the animal model of depressive disorder induced by repeated administration of a low dose of reserpine: behavioral and neurochemical studies in the rat. Neurotox Res 26:85-98

Aoyama K, Matsumura N, Watabe M, Wang F, Kikuchi-Utsumi K, Nakaki T (2011) Caffeine and uric acid mediate glutathione synthesis for neuroprotection. Neuroscience 181:206-215

Arnone D, Mclntosh AM, Ebmeier KP, Munafo MR, Anderson IM (2012) Magnetic resonance imaging studies in unipolar depression: systematic review and meta-regression analyses. Eur Neuropsychopharmacol 22:1-16

Barros-Miñones L, Goñi-Allo B, Suquia V, Beitia G, Aquirre N, Puerta E (2015) Contribution of dopamine to mitochondrial complex I inhibition and dopaminergic deficits caused by methylenedioxymethamphetamine in mice. Neuropharmacology 93:124-133

Behr GA, Moreira JC, Frey BN (2012) Preclinical and clinical evidence of antioxidant effects of antidepressant agents: implications for the pathophysiology of major depressive disorder. Oxidative Med Cell Longev 2012:609421. https://doi.org/10.1155/2012/609421

Bhattacharya SK, Satyan KS, Chakrabarti A (1997) Anxiogenic action of caffeine: an experimental study in rats. J Psychopharmacol 11:219-224

Blardi P, de Lalla A, Urso R, Auteri A, Dell'Erba A, Bossini L, Castrogiovanni P (2005) Activity of citalopram on adenosine and serotonin circulating levels in depressed patients. J Clin Psychopharmacol 25:262-266

Bortolato M, Chen K, Shih JC (2008) Monoamine oxidase inactivation: from pathophysiology to therapeutics. Adv Drug Deliv Rev 60:1527-1533

Brown RE, Corey SC, Moore AK (1999) Differences in measures of exploration and fear in MHC-congenic C57BL/6J and B6-H-2K mice. Behav Genet 29:263-271

Cappelletti S, Daria P, Sani G, Aromatario M (2015) Caffeine: cognitive and physical performance enhancer or psychoactive drug? Curr Neuropharmacol 13(2015):71-88

Charles HC, Lazeyras F, Krishnan KR, Boyko OB, Payne M, Moore D (1994) Brain choline in depression: in vivo detection of potential pharmacodynamic effects of antidepressant therapy using hydrogen localized spectroscopy. Prog. Neuropsychopharmacol. Biol Psychiatry 18:1121-1127

Ciarlone AE (1978) Further modification of a fluoromertric method for analyzing brain amines. Microchem J 23:9-12

Cunha RA, Agostinho PM (2010) Chronic caffeine consumption prevents memory disturbance in different animal models of memory decline. J Alzheimers Dis 20:S95-S116

Dale E, Bang-Andersen B, Sánchez C (2015) Emerging mechanisms and treatments for depression beyond SSRIs and SNRls. Biochem Pharmacol 95:81-97

Devasagayam TP, Kamat JP, Mohan H, Kesavan PC (1996) Caffeine as an antioxidant: inhibition of lipid peroxidation induced by reactive oxygen species. Biochim Biophys Acta 1282:63-70

El Yacoubi M, Ledent C, Parmentier M, Bertorelli R, Ongini E, Costentin J, Vaugeois JM (2001) Adenosine A2A receptor antagonists are potential antidepressants: evidence based on pharmacology and A2A receptor knockout mice. Br J Pharmacol 134:68-77

Erecińska M, Silver IA (1989) ATP and brain function. J Cereb Blood Flow Metab 9:2-19

Erickson JD, Eiden LE, Hoffman BJ (1992) Expression cloning of a reserpinesensitive vesicular monoamine transporter. Proc Natl Acad Sci U S A 89: 10993-10997

Ferré S (2016) Mechanisms of the psychostimulant effects of caffeine:implications for substance use disorder. Psychopharmacology 233(10):1963-1979

Ferré S, O'Connor WT, Svenningsson P, Björklund L, Lindberg J, Tinner B, Strömberg I, Goldstein M, Ögren SO, Ungerstedt U, Fredholm BB, Fuxe K (1996a) Dopamine D1 receptor-mediated facilitation of GABAergic neurotransmission in the rat strioentopenduncular pathway and its modulation by adenosine A1 receptor-mediated mechanisms. Eur J Neurosci 8:1545-1553

Ferré S, Popoli P, Tinner-Staines B, Fuxe K (1996b) Adenosine A1 receptordopamine D1 receptor interaction in the rat limbic system: modulation of dopamine D1 receptor antagonist binding sites. Neurosci Lett 208:109-112

Fisone G, Borgkvist A, Usiello A (2004) Caffeine as a psychomotor stimulant: mechanism of action. Cell Mol Life Sci 61:857-872

Fredholm BB (1995) Astra award lecture. Adenosine, adenosine receptorsand the actions of caffeine. Pharmacol Toxicol 76:93-101

Fredholm BB, Battig K, Holmen J, Nehlig A, Zvartau EE (1999) Actions of caffeine in the brain with special reference to factors that contribute to its widespread use. Pharmacol Rev 51:83-133

Fredholm BB, Chen JF, Cunha RA, Svenningsson P, Vaugeois JM (2005) Adenosine and brain function. Int Rev Neurobiol 63:191-270

Fryer JD, Lukas RJ (1999) Antidepressants noncompetitively inhibit nicotinic acetylcholine receptor function. J Neurochem 72:1117-1124

Gałecki P, Gałecka E, Maes M, Chamielec M, Orzechowska A, Bobińska K, Lewiński A, Szemraj J (2012) The expression of genes encoding for COX-2, MPO, iNOS, and SPLA2-IIA in patients with recurrent depressive disorder. J Affect Disord 138:360-366

Garrett BE, Griffiths RR (1997) The role of dopamine in the behavioral effects of caffeine in animals and humans. Pharmacol Biochem Behav 53:533-541

Gaweł S, Wardas M, Niedworok E, Wardas P (2004) Malondialdehyde (MDA) as a lipid peroxidation marker. Wiad Lek 57:453-455 
Gersner R, Gordon-Kiwkowitz M, Zangen A (2009) Automated behavioral analysis of limbs' activity in the forced swim test. J Neurosci Methods 180:82-86

Gorun V, Proinov I, Baltescu V, Balaban G, Barzu O (1978) Modified Ellman procedure for assay of cholinesterases in crude enzymatic preparation. Anal Biochem 86(1):324-326

Guo X, Park Y, Freedman ND, Sinha R, Hollenbeck AR, Blair A, Chen H (2014) Sweetened beverages, coffee, and tea and depression risk among older US adults. PLoS One 9:e94715

Hashiguchi W, Nagatomo I, Akasaki Y, Uchida M, Tominaga M, Takigawa M (2001) Influences of caffeine to nitric oxide production and zonisamide concentration in the brain of seizure susceptible EL mice. Psychiatry Clin Neurosci 55:319-324

Hennings EC, Kiss JP, De Oliveira K, Toth PT, Vizi ES (1999) Nicotinic acetylcholine receptor antagonistic activity of monoamine uptake blockers in rat hippocampal slices. J Neurochem 73:1043-1050

Higley MJ, Picciotto MR (2014) Neuromodulation by acetylcholine: examples from schizophrenia and depression. Curr Opin Neurobiol 29:88-95

Holmes PV (2003) Rodent models of depression: reexamining validity without anthropomorphic inference. Crit Rev Neurobiol 15:143-174

Holtzman SG, Finn IB (1988) Tolerance to behavioral effects of caffeine in rats. Pharmacol Biochem Behav 29:411-418

Hsu CW, Wang CS, Chiu TH (2010) Caffeine and a selective adenosine $A_{2 A}$ receptor antagonist induce sensitization and cross-sensitization behavior associated with increased striatal dopamine in mice. J Biomed Sci 17:4. https://doi.org/10.1186/1423-0127-17-4

Jakobsen JC, Katakam KK, Schou A, Hellmuth SG, Stallknecht SE, Leth-Møller K, Iversen M, Banke MB, Petersen IJ, Klingenberg SL, Krogh J, Ebert SE, Timm A, Lindschou J, Gluud C (2017) Selective serotonin reuptake inhibitors versus placebo in patients with major depressive disorder. A systematic review with meta-analysis and Trial Sequential Analysis. BMC Psychiatry 17:162. https:// doi.org/10.1186/s12888-017-1311-5

Janowsky DS, el- Yousef MK, Davis JM, Sekerke HJ (1972) A cholinergic-adrenergic hypothesis of mania and depression. Lancet 2:632-635

Jin MJ, Yoon CH, Ko HJ, Kim HM, Kim AS, Moon HN, Jung SP (2016) The relationship of caffeine intake with depression, anxiety, stress, and sleep in Korean adolescents. Korean J Fam Med 37:111-116

Karcz-Kubicha M, Antoniou K, Terasmaa A, Quarta D, Solinas M, Justinova Z, Pezzola A, Reggio R, Müller CE, Fuxe K, Goldberg SR, Popoli P, Ferré S (2003) Involvement of adenosine $\mathrm{A} 1$ and $\mathrm{A} 2 \mathrm{~A}$ receptors in the motor effects of caffeine after its acute and chronic administration. Neuropsychopharmacology 28:1281-1291

Kuzmin A, Johansson B, Gimenez L, Ögren S, Fredholm BB (2006) Combination of adenosine $\mathrm{A} 1$ and $\mathrm{A} 2 \mathrm{~A}$ receptor blocking agents induces caffeine-like locomotor stimulation in mice. Eur Neuropsychopharmacol 16:129-136

Maes M, Galecki P, Chang YS, Berk M (2011) A review on the oxidative and nitrosative stress (O\&NS) pathways in major depression and their possible contribution to the (neuro) degenerative processes in that illness. Prog Neuro-Psychopharmacol Biol Psychiatry 35:676-692

Mathers CD, Loncar D (2006) Projections of global mortality and burden of disease from 2002 to 2030. PLoS Med 3:e442

Mineur YS, Obayemi A, Wigestrand MB, Fote GM, Calarco CA, Li AM, Picciotto MR (2013) Cholinergic signaling in the hippocampus regulates social stress resilience and anxiety- and depression-like behavior. Proc Natl Acad Sci U S A 110:3573-3578

Moron MS, Depierre JW, Mannervik B (1979) Levels of glutathione, glutathione reductase and glutathione S-transferase activities in rat lung and liver. Biochem Biophys Acta 582:67-67

Moshage H, Kok B, Huizenga JR, Jansen PL (1995) Nitrite and nitrate determination in plasma: a critical evaluation. Clin Chem 41(6 Pt 1):892-896

Nehlig A, Daval J-L, Debry G (1992) Caffeine and the central nervous system: mechanisms of action, biochemical, metabolic and psychostimulant effects. Brain Res Rev 17:139-170

Pham NM, Nanri A, Kurotani K, Kuwahara K, Kume A, Sato M, Hayabuchi H, Mizoue T (2014) Green tea and coffee consumption is inversely associated with depressive symptoms in a Japanese working population. Public Health Nutr 17:625-633

Porkka-Heiskanen T (1999) Adenosine in sleep and wakefulness. Ann Med 31:125-129

Ruiz-Larrea MB, Leal AM, Liza M, Lacort M, de Groot H (1994) Antioxidant effects of estradiol and 2-hydroxyestradiol on iron-induced lipid peroxidation of rat liver microsomes. Steroids 59:383-388

Ruusunen A, Lehto SM, Tolmunen T, Mursu J, Kaplan GA, Voutilainen S (2010) Coffee, tea and caffeine intake and the risk of severe depression in middle-aged
Finnish men: the Kuopio ischaemic heart disease risk factor study. Public Health Nutr 13:1215-1220

Saricicek A, Esterlis I, Maloney KH, Mineur YS, Ruf BM, Muralidharan A, Chen II, Cosgrove KP, Kerestes $\mathrm{R}$, Ghose S, Tamminga CA, Pittman B, Bois F, Tamagnan G, Seibyl J, Picciotto MR, Staley JK, Bhagwagar Z (2012) Persistent $\beta 2{ }^{*}$-nicotinic acetylcholinergic receptor dysfunction in major depressive disorder. Am J Psychiatry 169:851-859

Schechter LE, Ring RH, Bayer CE, Haghes ZA, Khawaja X, Malberg JE, Rosenzweig-Lipson S (2005) Innovative approaches for the development of antidepressant drugs: current and future strategies. J Am Soc Exp Neurotherap 2:590-611

Shi X, Dalal NS, Jain AC (1991) Antioxidant behaviour of caffeine: efficient scavenging of hydroxyl radicals. Food Chem Toxicol 29:1-6

Souza MA, Mota BC, Gerbatin RR, Rodrigues FS, Castro M, Fighera MR, Royes LF (2013) Antioxidant activity elicited by low dose of caffeine attenuates pentylenetetrazol-induced seizures and oxidative damage in rats. Neurochem Int 62:821-830

Svenningsson P, Nomikos GG, Fredholm BB (1999) The stimulatory action and the development of tolerance to caffeine is associated with alterations in gene expression in specific brain regions. J Neurosci 19:4011-4022

Toda N, Ayajiki K, Okamura T (2009) Cerebral blood flow regulation by nitric oxide in neurological disorders. Can J Physiol Pharmacol 87:581-594

Tsakiris S, Angelogianni P, Schulpis KH, Behrakis P (2000) Protective effect of I-cysteine and glutathione on rat brain $\mathrm{Na}+, \mathrm{K}+$ ATPase inhibition induced by free radicals. Z Naturforsch 55:271-277

Wang L, Shen X, Wu Y, Zhang D (2016) Coffee and caffeine consumption and depression: A meta-analysis of observational studies. Aust NZJ Psychiatry 50: 228-242

Wasik A, Romańska I, Antkiewicz-Michaluk L (2009) 1-Benzyl-1,2,3,4tetrahydroisoquinoline, an endogenous parkinsonism-inducing toxin, strongly potentiates MAO-dependent dopamine oxidation and impairs dopamine release: ex vivo and in vivo neurochemical studies. Neurotox Res 15:15-23

Williams M (1987) Purine receptors in mammalian tissues: pharmacology and functional significance. Annu Rev Pharmacol Toxicol 27:315-345

Youdim MB, Edmondson D, Tipton KF (2006) The therapeutic potential of monoamine oxidase inhibitors. Nat Rev Neurosci 7:295-309

\section{Submit your manuscript to a SpringerOpen ${ }^{\odot}$ journal and benefit from:}

- Convenient online submission

- Rigorous peer review

- Open access: articles freely available online

High visibility within the field

- Retaining the copyright to your article

Submit your next manuscript at $\boldsymbol{\nabla}$ springeropen.com 